\title{
Case Report: A castration-resistant terminal prostate cancer patient's survival prolonged after practicing Falun Gong
}

\section{[version 1; peer review: 1 not approved]}

\author{
Yu-Hong Dong (iD), Shawn Wu2, Ann Corson33,4, Kai-Hsiung Hsu(iD5 \\ ${ }^{1}$ SunRegen Healthcare AG, Allschwil, 4123, Switzerland \\ ${ }^{2}$ Qmetrics Techologies, Pittsford, NY, 14534, USA \\ ${ }^{3}$ Biomedical Science Department, Fei Tian College, Middletown, NY, 10940, USA \\ ${ }^{4}$ Integrative Family Medicine, Kennett Square, PA, 19348, USA \\ ${ }^{5}$ National Ilan University, Yilan, 260, Taiwan
}

\begin{tabular}{l} 
V1 First published: 22 Oct 2019, 8:1786 \\
https://doi.org/10.12688/f1000research.20824.1 \\
Second version: 25 Feb 2020, 8:1786 \\
https://doi.org/10.12688/f1000research.20824.2 \\
Latest published: 14 Dec 2020, 8:1786 \\
https://doi.org/10.12688/f1000research.20824.3 \\
\hline
\end{tabular}

\section{Abstract}

Background: Most metastatic prostate cancer patients receive androgen deprivation therapy (ADT) as the mainstay of treatment. Unfortunately, patients ultimately progress to castration resistance.

Clinical finding and diagnosis: We describe a man in his eighties who developed stage IV, M1b prostate cancer, and multiple $(\geq 5)$ bone metastases who required the aid of a walker to ambulate. Without treatment, his treating physician predicted he would survive 6 months. Interventions and outcomes: The patient initially responded well to treatment with ADT, but during the 80-89th week of treatment he developed castration resistance. ADT was then discontinued. He subsequently began practicing Falun Gong (FLG) as an alternative form of care. Within one year of constant practice, he became able to walk independently, his bone metastases disappeared, and he also enjoyed better psychosocial functioning. His treating physician assessed that his prostate malignancy was "clinically, under control" and "his overall functional status is excellent." The patient survived a total of 263 weeks (61.4 months) post diagnosis, including 174 weeks (40.6 months) after developing castration resistance.

Conclusion: This castration-resistant terminal prostate cancer patient gained significant clinical benefits after practicing Falun Gong.

\section{Keywords}

Castration-resistant prostate cancer, Metastatic prostate cancer, Survival, Falun Gong, Eudaimonic well-being, Alternative medicine, Mind-body Medicine, Mindfulness

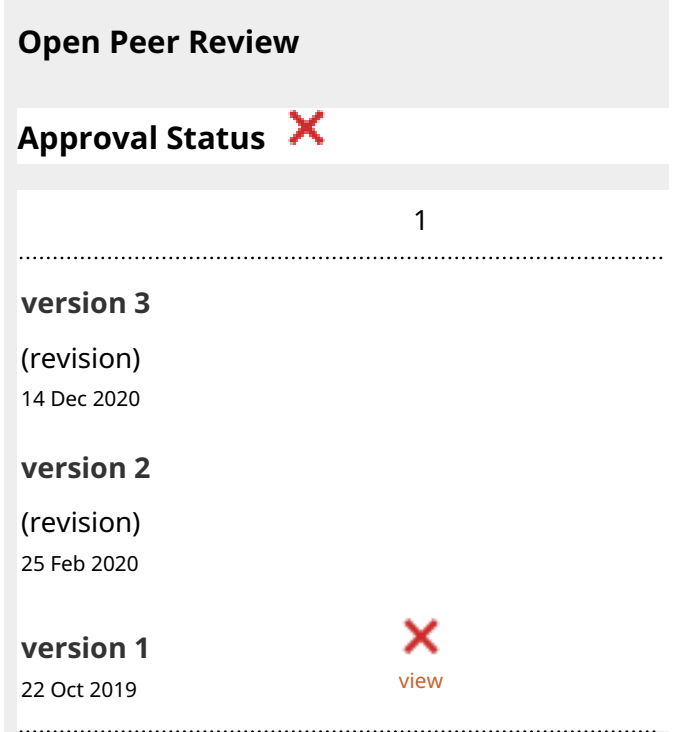

1. Laurence Klotz, Sunnybrook Health Sciences Centre, Toronto, Canada

Any reports and responses or comments on the article can be found at the end of the article. 


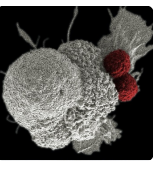

This article is included in the Oncology

gateway.

Corresponding author: Kai-Hsiung Hsu (khhsu@niu.edu.tw)

Author roles: Dong YH: Conceptualization, Data Curation, Formal Analysis, Investigation, Methodology, Project Administration, Writing - Original Draft Preparation, Writing - Review \& Editing; Wu S: Formal Analysis, Investigation, Visualization, Writing - Review \& Editing; Corson A: Methodology, Validation, Writing - Review \& Editing; Hsu KH: Conceptualization, Investigation, Methodology, Supervision, Validation, Visualization, Writing - Review \& Editing

Competing interests: No financial competing interests are disclosed. Non-financial competing interests: All authors are Falun Dafa practitioners. This status helps the authors have access to this valuable case. All the original data was completely obtained from the hospital physicians at the request of the patient and then shared with authors for publication at the consent of the patient. No other competing interests were disclosed.

Grant information: The author(s) declared that no grants were involved in supporting this work.

Copyright: $\odot 2019$ Dong YH et al. This is an open access article distributed under the terms of the Creative Commons Attribution License , which permits unrestricted use, distribution, and reproduction in any medium, provided the original work is properly cited.

How to cite this article: Dong YH, Wu S, Corson A and Hsu KH. Case Report: A castration-resistant terminal prostate cancer patient's survival prolonged after practicing Falun Gong [version 1; peer review: 1 not approved] F1000Research 2019, 8:1786 https://doi.org/10.12688/f1000research.20824.1

First published: 22 Oct 2019, 8:1786 https://doi.org/10.12688/f1000research.20824.1 


\section{Introduction}

Prostate cancer is the second most common cancer $^{\mathrm{a}}$ and the fifth leading cause of cancer death in men $^{\mathrm{b}}$ worldwide. In the United States, it is the most prevalent cancer and the second leading cause of cancer death in men ${ }^{c}$. The five-year overall survival in metastatic prostate cancer patients aged $\geq 75$ years is $13.6 \%{ }^{1}$. Androgen deprivation therapy (ADT), either by means of bilateral orchiectomy or the administration of a gonadotropinreleasing hormone $(\mathrm{GnRH})$ agonist or antagonist, is the mainstay of treatment for metastatic prostate cancer $^{2}$. In most metastatic prostate cancer patients, ADT is initially effective, but its response is not sustained and patients ultimately progress to castration resistance ${ }^{3}$.

In recent years there has been a growing awareness of oriental meditative approaches for health and wellness in the West. Deeply rooted in thousands of years of Chinese cultural history, Qigong is a traditional Chinese mind-body practice that uses qi (vital energy) and consciousness cultivation to achieve an optimal health state. Falun Gong (FLG) is a unique type of ancient qigong practice based on the principles of "truthfulness-compassion-tolerance". The practice of FLG includes reading the main teachings, Zhuan Falun ${ }^{d}$ and performing five sets of slow, gentle, meditative exercises ${ }^{\mathrm{e}}$.

Recently, we prospectively followed a terminal stage IV prostate cancer patient in his eighties, who relapsed after ADT and then began practicing FLG. This is the first well documented castration-resistant prostate cancer case whose survival was significantly prolonged after practicing FLG.

\section{Case report}

An 80-year-old Chinese man was a retired professor at a university in the USA. He presented to a urology clinic in 2014 complaining of bone pain, fatigue, and an elevated prostate specific antigen (PSA; ranging from 94.7 to $126.6 \mathrm{ng} / \mathrm{ml}$; normal range: $0.6-12.4 \mathrm{ng} / \mathrm{ml}$ for $75-79$ years born in China ${ }^{4}$ ) for one year. He had a 20-year history of hypothyroidism treated with Synthroid ${ }^{\mathrm{TM}}(75 \mu \mathrm{g} / \mathrm{day})$, a hernia operation in 2003 , and an implanted pacemaker in 2011. He had been diagnosed with benign prostate hyperplasia in 2004 and his baseline PSA values ranged from 4.1 to $8.6 \mathrm{ng} / \mathrm{ml}$ between 1996 and 2006. There was a family history of cancer. The patient required the aid of a walker to ambulate. Digital rectal exam (DRE) revealed a "very hard, very nodular and fixed prostate." PSA was $468 \mathrm{ng} / \mathrm{ml}$ on presentation. Transrectal ultrasound image showed the prostate to be $63 \times 57 \times 53 \mathrm{~mm}^{3}$ with disrupted capsule, abnormal inhomogeneous peripheral zone, scattered calcifications, and no median lobe. The prostate biopsy pathology report revealed an

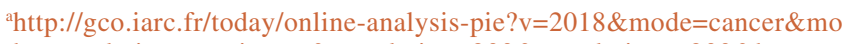
de_population $=$ continents $\&$ population $=900 \&$ populations $=900 \& \mathrm{key}=$ tot al\&sex $=1 \&$ cancer $=39 \&$ type $=0 \&$ statistic $=5 \&$ prevalence $=0 \&$ population group $=0 \&$ ages_group $\% 5 \mathrm{~B} \% 5 \mathrm{D}=0 \&$ ages_group $\% 5 \mathrm{~B} \% 5 \mathrm{D}=17 \& \mathrm{nb}$ items $=7 \&$ group_cancer $=1 \&$ include_nmsc $=1 \&$ include_nmsc other $=1 \&$ half_pie $=0 \&$ donut $=0 \&$ population_group_globocan_id $=$

${ }^{b}$ http://gco.iarc.fr/today/online-analysis-pie?v=2018\&mode=cancer \&mo de_population $=$ continents $\&$ population $=900 \&$ populations $=900 \& \mathrm{key}=$ tot adenocarcinoma with a Gleason Score $9(4+5$ or $5+4)$ in all lobes with 40-80\% cancer infiltration (Figure 1). Whole-body bone scan was highly suspicious for numerous osseous metastases in the lumbar and thoracic spine as well as in the left iliac bone of the pelvis, some areas of the sacrum and in the left 9th rib (Figure 2). CT scan findings were consistent with the bone scan (Figure 2). The patient was diagnosed with terminal stage IV, M1b metastatic prostate adenocarcinoma with extensive $(\geq 5)$ bone metastases. His treating physician predicted that without effective treatment he would have a life expectancy of only 6 months.

The patient was started on degarelix (240mg, 80mg, $80 \mathrm{mg}$ at month intervals) and bicalutamide $50 \mathrm{mg}$ daily. Survival was monitored by symptoms and serum PSA. Quality of life (QoL) was assessed with the SF-8 ${ }^{\mathrm{TM}}$ questionnaire (Table 1). Psychosocial functioning was evaluated using an adapted, simplified six-part questionnaire that assessed the patient's status of positive thinking, happiness, altruism, emotional control and purpose of life. All these parameters have been systemically researched in a number of mindfulness psychological studies and commonly used in psychosocial functioning outcomes ${ }^{5}$ (Table 2).

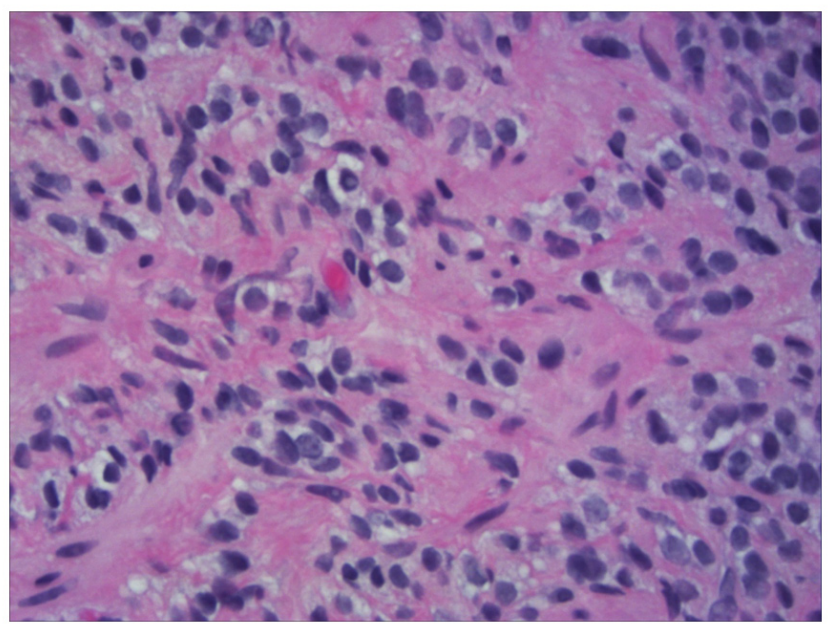

Figure 1. Core biopsy of the patient's prostatic adenocarcinoma (hematoxylin and eosin stain). The adenocarcinoma consists of poorly formed or fused glandular acini (Gleason grade 4) and aggregates, cords and solid foci not recognizable as acini (Gleason grade 5), resulting in the Gleason score of $9(4+5)$. The Gleason score is the sum of two most prevalent histologic grades in a prostate adenocarcinoma, rated on a scale of $1-5$, with 5 being the most clinically aggressive.

al \&sex $=1 \&$ cancer $=39 \&$ type $=1 \&$ statistic $=5 \&$ prevalence $=0 \&$ population group $=0 \&$ ages_group $\% 5 \mathrm{~B} \% 5 \mathrm{D}=0 \&$ ages_group $\% 5 \mathrm{~B} \% 5 \mathrm{D}=17 \& \mathrm{nb}$ items $=7 \&$ group_cancer $=1 \&$ include_nmsc $=1 \&$ include_nmsc other $=1 \&$ half_pie $=0 \&$ donut $=0 \&$ population_group_globocan_id $=$

chttps://gis.cdc.gov/Cancer/USCS/DataViz.html

${ }^{d}$ https://falundafa.org/eng/eng/pdf/ZFL2014.pdf

ehttp://en.falundafa.org/eng/html/dymf_2014/dymf_2014_2.htm 


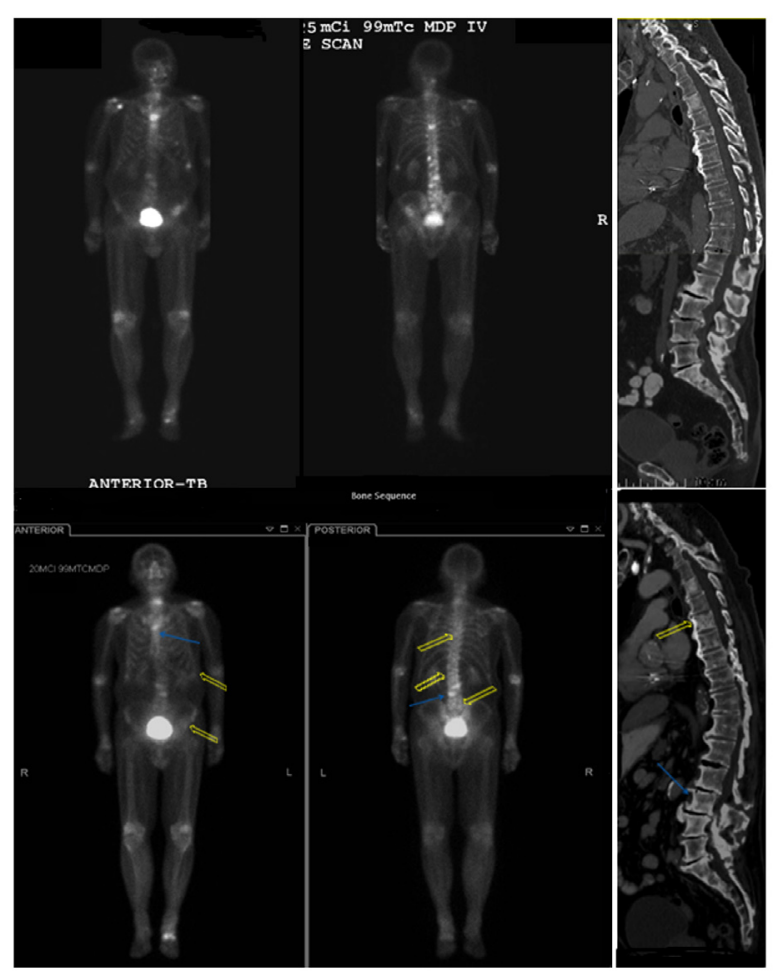

Figure 2. Comparison of whole-body bone scan and spine CT images before and after Falun Gong (FLG) practice. Upper Row: before FLG practice (May-2014); Lower Row: after FLG practice (Nov-2016); Left and Middle Columns: anterior and posterior views of the bone scan; Right Column: post-processed (Multiplanar Reformation) Spine CT. The yellow arrows denote the normal uptake level of tracer corresponding to the original bone metastatic foci in the upper row, as shown at the sites of the left $9^{\text {th }}$ rib region, thoracic vertebra (T7, also shown on CT image), sacral vertebrae region, and left iliac region, indicating the disappearance of cancer. The blue arrows denote degenerative bone regions with mild increased tracer uptake in sternum region and lumbar spine region but without evidence of neoplastic lesions. Degenerative appearances of bone and joint were also observed in the upper and lower extremities (bone scan) as well as in the spine (CT image).

The patient's bone pain was gone within 5 days. After five weeks, his PSA dropped to $4.5 \mathrm{ng} / \mathrm{ml}$. At week 14, degarelix was replaced with leuprolide acetate at a dose of $22.5 \mathrm{mg}$ quarterly. PSA levels remained at $0-0.2 \mathrm{ng} / \mathrm{ml}$ until week 68 . At week 80, his PSA rose to $1.4 \mathrm{ng} / \mathrm{ml}$, and his physician discontinued bicalutamide due to suspicion of cancer relapse. PSA continued to increase to $2.4 \mathrm{ng} / \mathrm{ml}$ at week 84 and to $3.7 \mathrm{ng} / \mathrm{ml}$ at week 89 . (Figure 3, Table 3)

The physician planned to use abiraterone acetate plus prednisone or enzalutamide if the PSA rose to $10 \mathrm{ng} / \mathrm{ml}$. The patient was not pleased with either choice because of the increased risk of side effects and limited survival benefits. ADT was then discontinued. At week 89, the patient began practicing FLG. When he watched the FLG video for the first time, the patient reported that he felt as if substantial high energy matter was plugged into his two lower legs. He could sense the flow of energy and the warmth induced by the energy during practicing. In the past, during cold winter nights, the patient had a tendency to get cramps in his legs. To prevent this, he had been using a hot water bottle under the quilt while sleeping for many years. Soon after starting to practice FLG, the patient reported he did not need a hot water bottle anymore.
At week 94, the patient's PSA reversed its increasing trend by dropping to $0.6 \mathrm{ng} / \mathrm{ml}$ (Figure 3, Table 3). At week 106, he no longer needed the assistance of a walker. At weeks 130 and 133, no osseous metastases were seen on either CT or whole-body bone scan (Figure 2). At week 151, DRE revealed that the prostate was softer and smaller than before.

Following ADT, the patient experienced adverse events including right foot swelling, wheezing, and hot flashes for about one year, all of which, the patient reported, had gradually disappeared after practicing FLG.

The patient's QoL improved greatly with FLG practice (Table 1). He was even able to go up a 14-step stairway without stopping halfway or developing shortness of breath with exertion on stairs he had before practicing FLG (Extended data: Video S1). Additionally, the patient reported the following sequential trend of psychosocial functioning improvement: starting FLG practice, finding the purpose of life, developing positive thinking, having a better temperament, experiencing symptom improvement, feeling happier and less depressed, and becoming more altruistic (Table 2). At week 219, based on the extended survival, absence of symptoms, disappearance of bone 


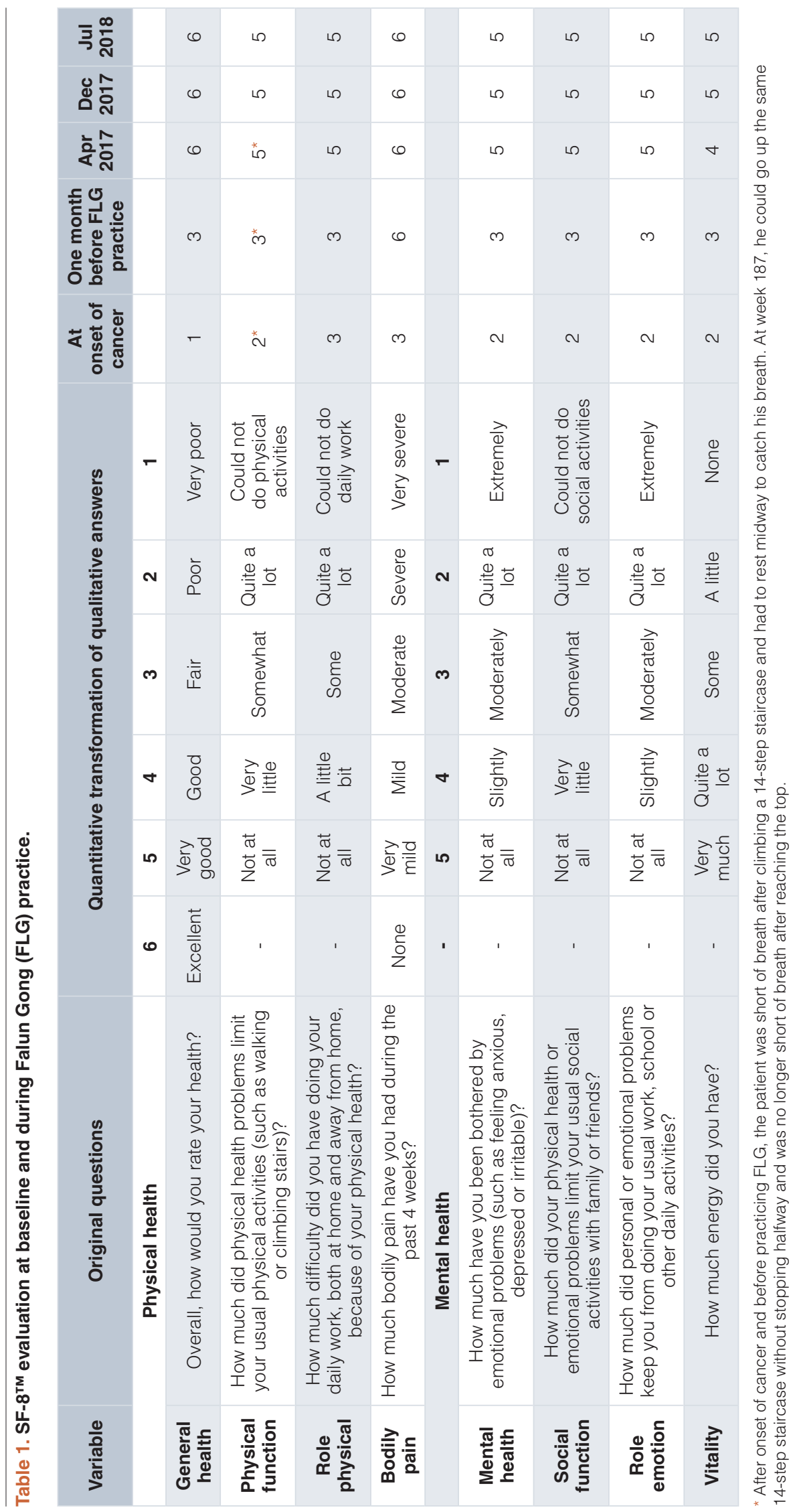


Table 2. Psychosocial functioning evaluation.

\begin{tabular}{|c|c|c|}
\hline & At Week 154 & At Week 218 \\
\hline \multicolumn{3}{|l|}{ Compared to before practicing Falun Gong (FLG): } \\
\hline 1) Do you think more positively now? & Yes & Yes \\
\hline 2) Do you feel happier or less depressed? & Yes & Yes \\
\hline 3) Have you become more altruistic? & Yes & Yes \\
\hline 4) Have you found the purpose of life? & Yes & Yes \\
\hline 5) Do you have a better temper? & Yes & Yes \\
\hline $\begin{array}{l}\text { 6) Would you please relate the chronological } \\
\text { sequence for the spiritual-mental changes (as } \\
\text { noted in questions } 1-5 \text { ) and your symptomatic } \\
\text { improvements after starting FLG practice? }\end{array}$ & $\begin{array}{l}\text { The subject related the following } \\
\text { sequence of events: } \\
\text { 1. Starting FLG practice; } \\
\text { 2. Finding purpose of life; } \\
\text { 3. Thinking more positively; } \\
\text { 4. Developing a better temper; } \\
\text { 5. Experiencing symptomatic } \\
\text { improvement; } \\
\text { 6. Becoming happier and less } \\
\text { depressed; } \\
\text { 7. Becoming more altruistic. }\end{array}$ & $\begin{array}{l}\text { The subject confirmed } \\
\text { with the same answers } \\
\text { as Week } 154 \text {. }\end{array}$ \\
\hline
\end{tabular}

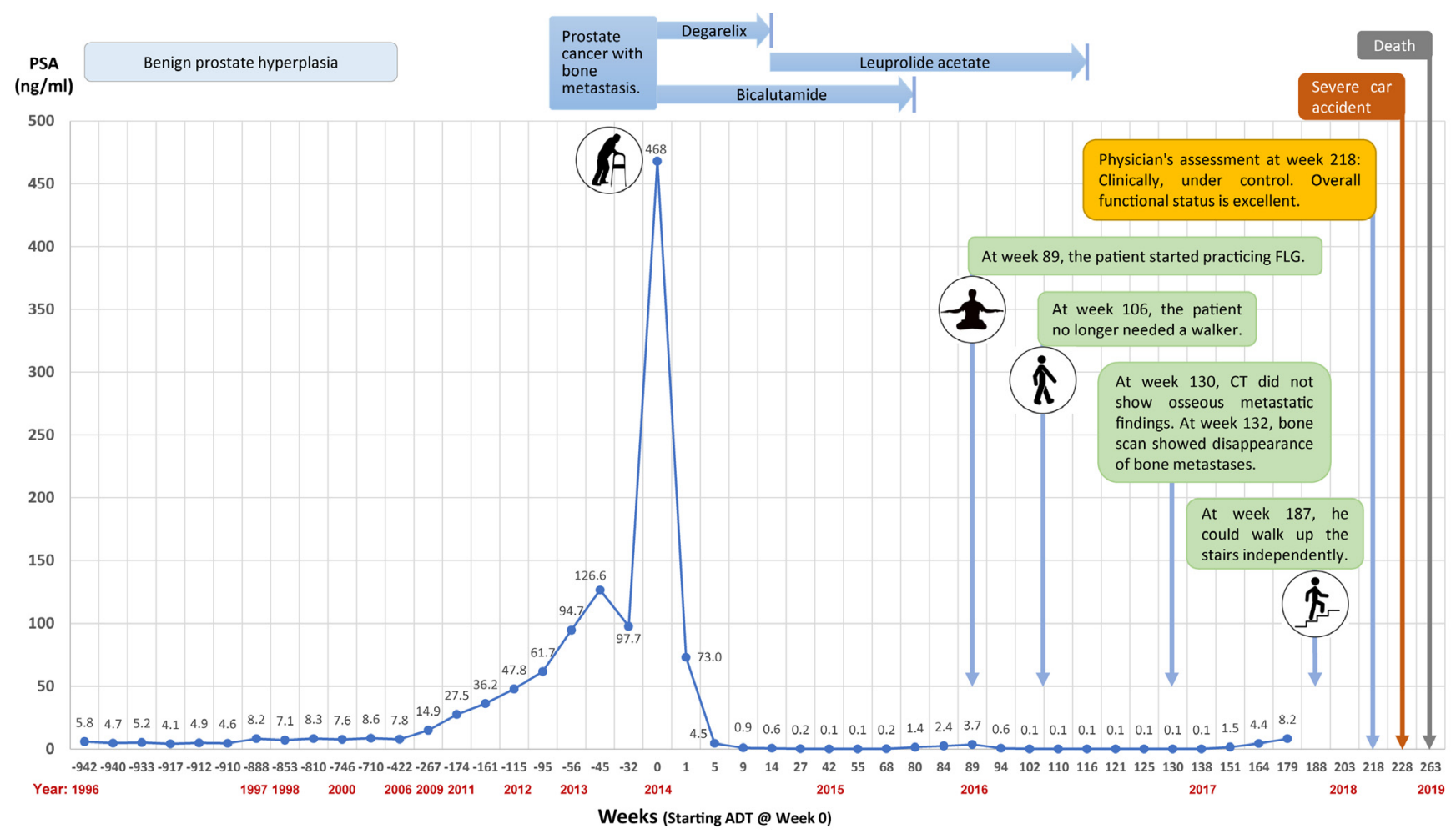

Figure 3. Prostate specific antigen (PSA) at baseline, and during androgen deprivation therapy and Falun Gong practice. In 19962006 the patient's PSA was 4.1-8.6 $\mathrm{ng} / \mathrm{ml}$. Before ADT, his PSA was $468 \mathrm{ng} / \mathrm{ml}$. PSA decreased to 0 within five weeks after ADT and remained at $<0.9 \mathrm{ng} / \mathrm{ml}$. At week 80 , PSA increased to $1.4 \mathrm{ng} / \mathrm{ml}$, and bicalutamide was stopped. At week 89 , PSA increased to $3.7 \mathrm{ng} / \mathrm{ml}$, and he started FLG practice. PSA declined to $0.6 \mathrm{ng} / \mathrm{ml}$ at week 94 . The last PSA were $4.4-8.2 \mathrm{ng} / \mathrm{ml}$, within his baseline levels $(4.1-8.6 \mathrm{ng} / \mathrm{ml})$ in 1996-2006. Each point stands for the PSA recorded at various times and the step size in time is not even. 


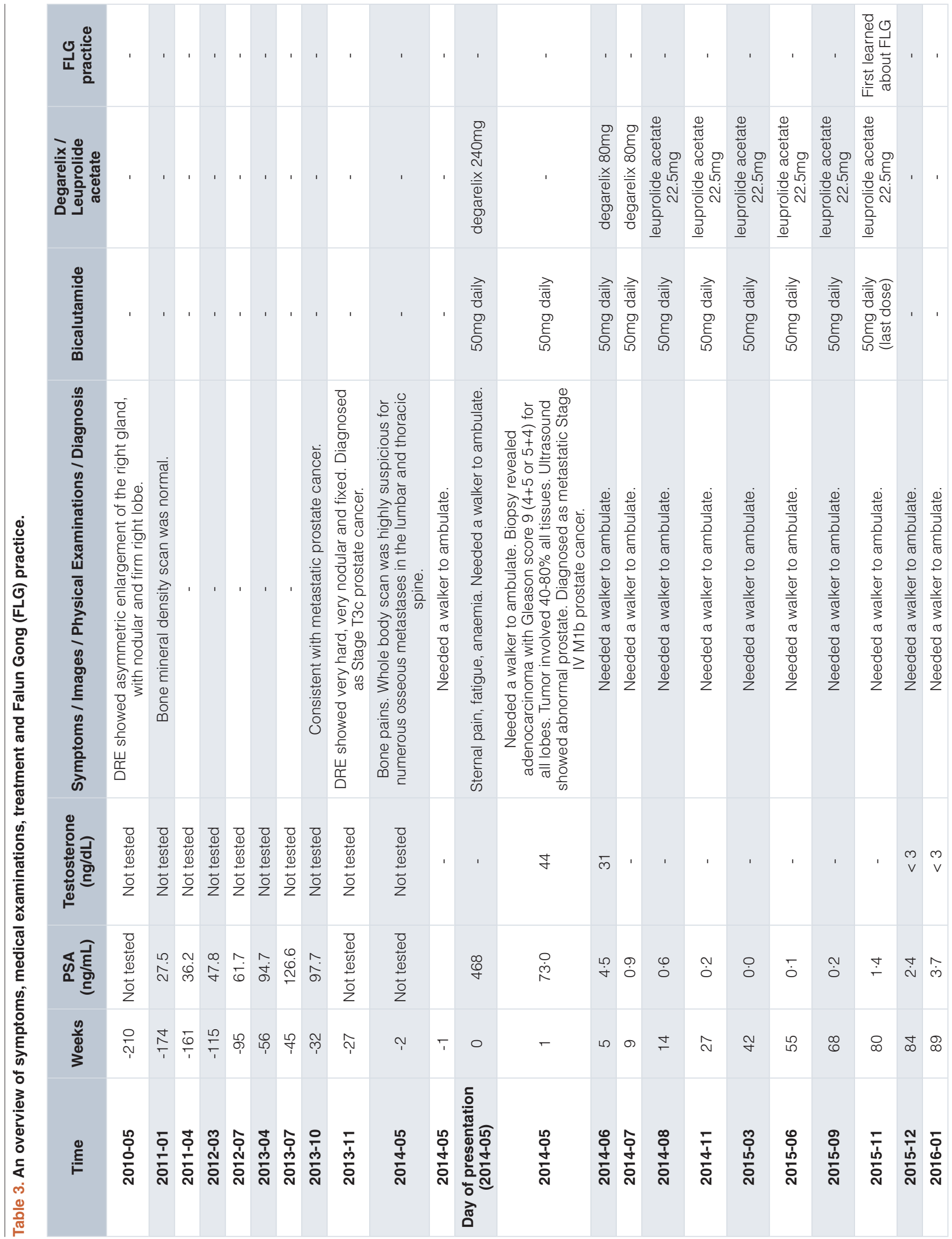




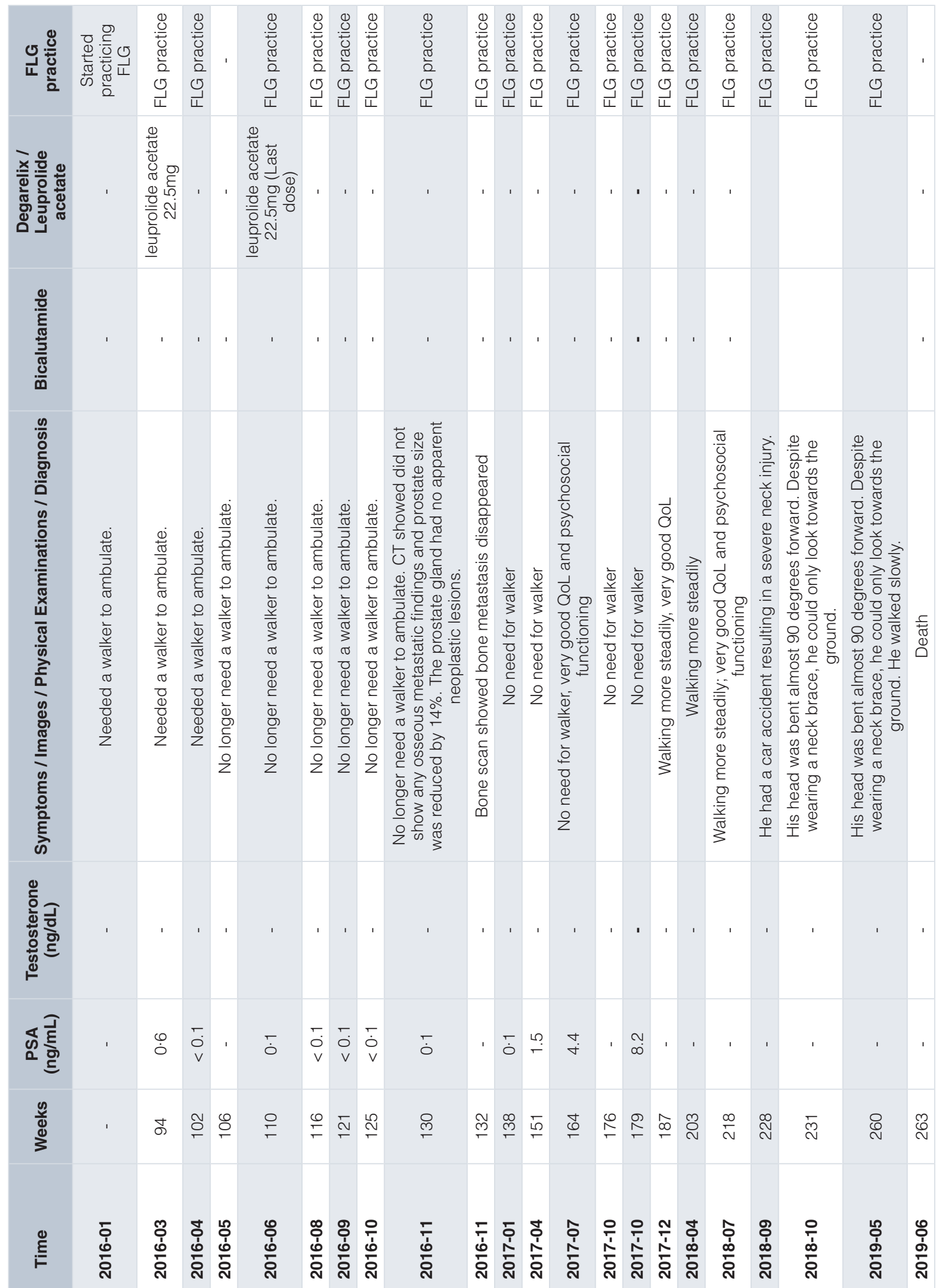


metastases, improved QoL and psychosocial functioning, his treating physician assessed that his prostate malignancy was "clinically, under control" and "his overall functional status is excellent." The patient reported to be living a healthy life with good physical and mental status. He shared his experience as a terminal cancer survivor in the hospital support group as well as with the local medical community.

On week 228, the patient had a car accident which resulted in a severe neck injury and decreased ability to walk. On week 263 , the patient was found dead at home from unknown causes. Three days before his death, he had spoken with us and denied any signs or symptoms of cancer relapse.

\section{Discussion}

The case presented here is a castration-resistant metastatic prostate cancer patient in his eighties. Prostate cancer patients receiving ADT inevitably develop castration-resistance within a median relapse time of 18 months $^{6}$ due to prostate cancer cells developing mechanisms to proliferate despite castrate levels of testosterone. M1 castrate-resistant prostate cancer patients with a high number of skeletal metastasis $(\geq 5)$ have a considerably poorer progression-free survival of 8.4 months and overall survival (OS) of 18.7 months, compared to patients with 1-4 bone metastases? .

The terminal prostate cancer patient in our case had a Gleason Score 9, a PSA of $468 \mathrm{ng} / \mathrm{ml}$, and high number of bone metastases $(\geq 5)$. Even with an initial response to ADT treatment, he still became castration resistant. After starting FLG practice, his PSA came down, he could walk independently, and his bone metastases disappeared within a short time frame. After developing castrate resistance and stopping ADT, he survived for an additional 174 weeks (40.6 months), which is far longer than the reported OS of 18.7 months in patients with similar clinical conditions? ${ }^{7}$. The close temporal relationship between FLG practice and significant cancer improvement and the absence of any other treatment after starting FLG practice suggest that FLG practice resulted in a holistic and beneficial effect in this terminal prostate cancer patient. Moreover, the patient reported a good QoL free of cancer symptoms until he died of a non-cancer related cause, possibly due to the sequela of his severe car accident and/or his pacemaker-related cardiac condition.

As the pituitary-gonadal system is usually restored within 4 to 12 weeks after leuprolide acetate is discontinued ${ }^{f}$, the later rise in the patient's most recent PSA level might reflect his baseline PSA levels of 20 years ago. Additionally, PSA levels are also known to increase with age. A cohort study (the Concord Health and Ageing in Men Project, CHAMP) involving a

fhttps://www.accessdata.fda.gov/drugsatfda_docs/label/2014/020517s036_ 019732s041lbl.pdf representative sample of 1434 eligible community-dwelling men with no diagnosis of prostate cancer reported a $5^{\text {th }}$ to $95^{\text {th }}$ percentile range of $0.6-12.4 \mathrm{ng} / \mathrm{ml}$ of serum PSA level in men aged 75-79 and born in China ${ }^{4}$.

While there are anecdotical testimonies from terminal cancer patients revealing they survived longer than expected after practicing $\mathrm{FLG}^{8,9}$, this is the first case report documented with detailed medical records. According to the canon of traditional Chinese medicine, the Yellow Emperor's Classic of Medicine, people may enjoy a long, disease-free life by cultivating the mind and following upright moral principles ${ }^{10}$. The emerging discipline of psychoneuroimmunology has begun to disclose the relationship between psychological, neurological and immunological systems. For example, eudaimonic well-being is found to be associated with decreased expression of transcriptional response to adversity profile involving inflammation mediated neoplastic diseases ${ }^{11}$, decreased tumour growth and progression-related norepinephrine ${ }^{12}$. The patient presented here experienced symptom improvement soon after reading Zhuan Falun and accepting the principles of "truthfulnesscompassion-tolerance", suggesting that the improvement of moral and spiritual character also plays a significant role in the improvement of health.

\section{Conclusions}

We describe in detail for the first time in the medical literature, the clinical course of a terminal prostate cancer case with relapse to ADT followed by FLG practice, an ancient Qigong practice originating from China. Most of the patient's prostate cancer signs and symptoms disappeared quickly after FLG practice, accompanied with greatly improved psychosocial functioning and quality of life. We conclude that this terminal prostate cancer case gained clinical benefits through practicing FLG. Although the mechanism by which FLG practice caused improvement is not yet well understood, its effects are identifiable and measurable. Thus, the practice of FLG deserves more investigation by the medical community.

\section{Patient perspective}

"My name is XXX. I had a teaching career as an Organic Chemistry Professor for 37 years at XXX before retiring in 2000. In May of 2014, I became a final stage, metastatic prostate cancer patient with bone pain, a 468 PSA, and an estimated life expectancy of less than half a year. I also required the aid of a walker to ambulate. After 19 months of androgen deprivation therapy (ADT), my cancer relapsed. Shortly prior to that relapse, I was very fortunate to have discovered a relatively new but rapidly growing mind and body cultivation practice known as Falun Gong that came originally from China.

On January 2016, I began to seriously engage in FLG cultivation practices involving reading moral teachings from a principle guidebook of Falun Dafa entitled "Zhuan Falun" and performing five different sets of Qigong exercises daily. A little over a month later, my PSA reversed its rising trend and 
dropped immediately to 0.6. Three months after that, I took my last Lupron treatment, thus ending the ADT therapy. After another five months, a new bone scan revealed the disappearance of metastases lesions. Today, I have been off any medicine, including cancer fighting medicine for 22 months. I am a healthy person with normal quality of life, no bone pain, full of energy, better tempered, more optimistic and positive. My own experience so far has demonstrated to my own satisfaction that cultivation of mind and body through practicing Falun Gong can be an effective healing and cost-effective way of combating cancer which is also free of undesirable side effects...

The magical effect of practicing Falun Gong had on my health made me appreciate the importance of elevating one's moral character to be in tune with the fundamental characteristics of the universe, namely, truthfulness, compassion, and tolerance. It also made me realize that there may very well be a set of supernormal science on human body that is quite unique, subtle, and highly deserving of greater attention and further studies by modern scientists."

Patient's Signature, July 2018

\section{Physician perspective}

Wednesday, July 2018: Patient seen on July XX. Overall, he is doing well. He is not depressed. He has no pain. He is currently on no medical therapy for his prostate cancer. $\mathrm{He}$ is optimistic and functional. All other systems reviewed and otherwise negative.

Assessment: Prostate malignancy: Clinically, under control. His overall functional status is excellent. Patient is comfortable with his spiritual approach to care.

\section{Consent}

Written informed consent for the publication of this case report and any associated images was obtained from the patient before his death.

\section{Data availability}

Underlying data

All data underlying the results are available as part of the article and no additional source data are required.

\section{Extended data}

Figshare: A castration-resistant terminal prostate cancer patient survived significantly longer and walked independently after practicing Falun Gong, https://doi.org/10.6084/m9.figshare. $9933296^{13}$

This project contains the following extended data:

- Video S1: This patient was diagnosed with terminal stage IV, M1b metastatic prostate adenocarcinoma with extensive $(\geq 5)$ bone metastases requiring the aid of a walker to ambulate. During treatment, he developed castration-resistance. After practicing Falun Gong, his bone metastases disappeared and he became able to walk independently. This video was taken three and a half years after the diagnosis of terminal cancer was made and less than two years after he started to practice Falun Gong. The patient walked up a 14-step stairway without stopping halfway and did not experience the shortness of breath with exertion on stairs he had before practicing Falun Gong.

Data are available under the terms of the Creative Commons Attribution 4.0 International license (CC-BY 4.0).

\section{Acknowledgements}

We thank Dr. Robert A. Goulart for sharing the pathological photos and reviewing the figure legend for the pathological photos in this paper. We thank Dr. Pamela Ellsworth for giving suggestions for the manuscript. We thank Rong-Sen Yang, MD, PhD, Dr. Chian-Feng Huang and Dr. Shi-Wei Huang for reviewing the manuscript. We thank Ms. June Fakkert for proof-reading.
1. Keating MJ, Giscombe L, Tannous T, et al.: Age-dependent overall survival benefit of androgen deprivation therapy for metastatic prostate cancer. $J$ Oncol Pharm Pract. 2019; 1078155219835597. PubMed Abstract | Publisher Full Text

2. Loblaw DA, Virgo KS, Nam R, et al.: Initial hormonal management of androgensensitive metastatic, recurrent, or progressive prostate cancer: 2006 update of an American Society of Clinical Oncology practice guideline. J Clin Oncol. 2007; 25(12): 1596-605.

PubMed Abstract | Publisher Full Text

3. Ritch $\mathrm{C}$, Cookson $\mathrm{M}$ : Recent trends in the management of advanced prostate cancer [version 1; peer review: 3 approved]. F1000Res. 2018; 7: pii: F1000 Faculty Rev-1513.

PubMed Abstract | Publisher Full Text | Free Full Text

4. Litchfield MJ, Cumming RG, Smith DP, et al.: Prostate-specific antigen levels in men aged 70 years and over: findings from the CHAMP study. Med $J$ Aust. 2012; 196(6): 395-8.

2012; 196(6): 395-8.
PubMed Abstract | Publisher Full Text

5. Luberto CM, Shinday N, Song R, et al.: A Systematic Review and Meta-analysis of the Effects of Meditation on Empathy, Compassion, and Prosocial Behaviors. Mindfulness (N Y). 2018; 9(3): 708-724.

PubMed Abstract | Publisher Full Text | Free Full Text

6. Crawford ED, Eisenberger MA, McLeod DG, et al.: A controlled trial of leuprolide with and without flutamide in prostatic carcinoma. N Engl J Med. 1989; 321(7): 419-24.

PubMed Abstract | Publisher Full Text

7. Tait C, Moore D, Hodgson C, et al.: Quantification of skeletal metastases in castrate-resistant prostate cancer predicts progression-free and overall survival. BJU Int. 2014; 114(6b): E70-E73. PubMed Abstract | Publisher Full Text

8. Clearwisdom editors: Life and Hope Renewed: The Healing Power of Falun Dafa. Mahwah, New Jersy: MINGHUI Publishing. 2008. Reference Source

9. McCoy WF, Zhang L: A Journey to Ultimate Health: Falun Gong Stories. First printing edition, Golden Lotus Press, 1998 Reference Source

10. Maoshing N: The Yellow Emperor's Classic of Medicine: A New Translation 
of the Neijing Suwen with Commentary. Boston, Massachusetts: Shambhala Publications. 1995; 1-2.

Reference Source

11. Fredrickson $\mathrm{BL}$, Grewen $\mathrm{KM}$, Coffey KA, et al:: A functional genomic perspective on human well-being. Proc Natl Acad Sci U S A. 2013; 110(33): 13684-9. PubMed Abstract | Publisher Full Text | Free Full Text

12. Davis LZ, Slavich GM, Thaker PH, et al.: Eudaimonic well-being and tumor norepinephrine in patients with epithelial ovarian cancer. Cancer. 2015 121(19): 3543-50.

PubMed Abstract | Publisher Full Text | Free Full Text

13. Dong YH, Wu S, Corson A, et al.: Figshare: A castration-resistant terminal prostate cancer patient survived significantly longer and walked independently after practicing Falun Gong. 2019. http://www.doi.org/10.6084/m9.figshare.9933296 


\section{Open Peer Review}

\section{Current Peer Review Status:}

\section{Version 1}

Reviewer Report 02 December 2019

\section{https://doi.org/10.5256/f1000research.22904.r56932}

(C) 2019 Klotz L. This is an open access peer review report distributed under the terms of the Creative Commons Attribution License, which permits unrestricted use, distribution, and reproduction in any medium, provided the original work is properly cited.

\section{Laurence Klotz}

Sunnybrook Research Institute, Sunnybrook Health Sciences Centre, Toronto, ON, M4N 3M5, Canada

This case could readily be explained by prolonged androgen suppression, which is common in elderly men after discontinuation of LHRH agonist. In the absence of serum testosterone levels after ADT was stopped, the case is not convincing. While I'm open to the effect of interventions such as this, it requires very convincing evidence.

On this basis I'd elect to reject this paper.

Is the background of the case's history and progression described in sufficient detail? Yes

Are enough details provided of any physical examination and diagnostic tests, treatment given and outcomes?

No

Is sufficient discussion included of the importance of the findings and their relevance to future understanding of disease processes, diagnosis or treatment? Yes

Is the case presented with sufficient detail to be useful for other practitioners? No

Competing Interests: No competing interests were disclosed.

Reviewer Expertise: Prostate cancer

I confirm that I have read this submission and believe that I have an appropriate level of 


\section{expertise to state that I do not consider it to be of an acceptable scientific standard, for reasons outlined above.}

\section{Author Response 28 Dec 2019}

\section{Yuhong Dong}

We thank Dr. Klotz for his valuable review, and summarize his questions into three parts and answer them accordingly below:

(1) This case could readily be explained by prolonged androgen suppression, which is common in elderly men after discontinuation of LHRH agonist.

Answer:

In this case, the use of LHRH agonist (leuprolide acetate) was discontinued at week 116 while the use of antiandrogen (bicalutamide) was discontinued at week 80 . The reviewer seemed to attribute the cascade of clinical responses that occurred in the patient to the discontinuation of LHRH agonist therapy. However, the patient already started to walk independently at week 106, indicating improvement in his bone metastases occurred before discontinuation of LHRH agonist and could not be attributed to the effect of prolonged androgen suppression.

Alternatively, the reviewer may refer to Antiandrogen Withdrawal Syndrome (AAWS) in the question instead of prolonged androgen suppression. AAWS, usually defined as $>50 \%$ decline in PSA following cessation of the antiandrogen, has been increasingly recognized and reviewed ${ }^{1,2,3}$. A large multi-institutional clinical trial (CALGB 9583) to investigate AAWS in androgen-independent prostate cancer patients (with a median age of 72 years) has showed that $11 \%$ of patients experienced AAWS with the median time to PSA progression at 5.9 months, and objective responses in measurable disease were observed in $2 \%$ of patients 4. In this case in his eighties, the time to PSA progression is 19.8 months (week 94-179) following the same criteria in that trial, while the survival time is 42.3 months (week 80-263), significantly greater than the median survival time of 16.7 months in the trial. We believe that even if AAWS might have played some role in this patient's clinical course, AAWS was not the sole factor contributing to longer survival and time to PSA progression. As indicated in that trial, patients in the AAWS + ketoconazole treatment arm have greater median time to PSA progression (8.6 months) and objective response rate $(20 \%)$ than do patients in the AAWS alone arm (5.9 months). FLG practice in this case started at week 89 might play a role comparable to ketoconazole therapy in the CALGB 9583 trial by adding anticancer activity. However, this enhancing role of ketoconazole therapy does not help prolong the median survival time (15.3 months) in the AAWS + ketoconazole treatment arm, actually a bit shorter than that in the AAWS alone arm (16.7 months). In contrast, FLG practice did help prolong the survival time to at least 42.3 months.

More importantly, without any effective drug treatment after developing castration resistance, the patent in this case lived without any symptoms, in excellent mental and spiritual health with a good quality of life without any cancer complications (such as bone pain, skeletal-related events, and urinary symptoms) or side effects associated with drug therapies. Additionally, a series of improvements in bone metastases occurred sequentially at week 106 (ambulating without a walker), week 130 (CT not showing osseous metastatic findings), week 132 (bone scan showing disappearance of bone metastases) and week 187 (walking up a 14-step stairway without stopping halfway). It is unlikely that all these beneficial effects could be attributed to AAWS alone. Holistic mind-body improvement, 
however, is commonly observed in the practice of FLG.

(2) In the absence of serum testosterone levels after ADT was stopped, the case is not convincing. Answer:

In Table 3, serum testosterone levels were tested at 44, 31, $<3$ and $<3$ (ng/dL) at week 1, 5, 84 and 89 , respectively. Testosterone levels dropped quickly at the beginning of ADT and stayed low $(<3 \mathrm{ng} / \mathrm{dL}$ ) after discontinuing antiandrogen at week 84 and 89 , as expected with the use of the LHRH agonist. However, PSA levels progressively rose between week $68(0.2$ $\mathrm{ng} / \mathrm{ml})$ and week $89(3.7 \mathrm{ng} / \mathrm{ml})$ despite low testosterone, indicating the cancer had become resistant to ADT. Thus, the testosterone level was not considered to have any role in the subsequent clinical events.

(3) "Are enough details provided of any physical examination and diagnostic tests, treatment given and outcomes?" "Is the case presented with sufficient detail to be useful for other practitioners?" The reviewer ticked "no" to both questions.

Answer:

Based on this case's well documented hospital records, we have provided adequate physical examinations, diagnostic tests (biopsy, PSA levels, testosterone levels, bone scan, CT scan), details of the treatments given, as well as the clinical outcomes. We believe this case report has been presented with ample medical details.

Clinical physicians and patients are likely to appreciate the significance of this case study's findings, especially if they consider the following three perspectives:

I. Survival

Such a significantly prolonged survival time is rarely reported in the medical literature and should be of great interest for those physicians who has managed similar patients.

In the CHAARTED trial, a high volume of metastatic prostate cancer was defined by the presence of visceral metastases or four or more bone lesions with at least one beyond the vertebral bodies and pelvis ${ }^{5}$. This 80 -year-old patient with a Gleason score of 9 met the definition of high volume metastatic prostate cancer as he had 5 bone metastases including one site beyond the vertebral body and pelvis (left 9th rib region). In the CHAARTED trial, the median life expectancy for an analogous patient was 32.2 months with patients seldom surviving longer than 60 months. Despite the multiple effective treatment for castration resistant prostate cancer, such as chemotherapy and second-generation anti-androgen therapy (zytiga, xtandi), provided by in this large clinical trial, the median life expectancy was just 32.2 months. In the non-academic medical community, the median life expectancy may be even shorter, perhaps around 27 months $^{6}$. The patient in this study, who practiced FLG, survived a total of 61.4 months ( 263 weeks) post-diagnosis, which is longer than comparable patients in both the CALGB 9583 and CHAARTED studies.

II. Quality of life

Without any effective drug treatment options after developing castration resistance, the patent in this case lived without any symptoms, in excellent mental and spiritual health, with a good quality of life, without any cancer complications (such as bone pain, skeletalrelated events, and urinary symptoms), or medication side effects. We believe that this case has been presented with sufficient evidence of the valuable clinical benefits this patient experienced from practicing FLG. This information is useful for physicians and patients alike who are searching for effective treatment options.

III. Cost

FLG practice is free, and anyone can start or stop the practice on his own. This may alleviate physicians and patients' financial concerns. 
The patient himself was a rigorous scientist who received orthodox scientific training and had a very good reputation in the organic chemistry community. His personal experience of practicing Falun Gong made him realize that "there may very well be a set of supernormal science on human body that is quite unique, subtle, and highly deserving of greater attention and further studies by modern scientists."

We appreciate Dr. Klotz's comments and hope this response answers his questions and concerns properly.

\section{References:}

1. Sartor AO, Tangen CM, Hussain MHA, et al.: Antiandrogen withdrawal in castraterefractory prostate cancer: a Southwest Oncology Group trial (SWOG 9426). Cancer 2008; 112(11): 2393-2400. PubMed I Full text

2. Leone G, Tucci M, Buttigliero C, et al.: Antiandrogen withdrawal syndrome (AAWS) in the treatment of patients with prostate cancer. Endocr Relat Cancer. 2018;25(1):R1-R9. PubMed I Full text

3. Lau YK, Chadha MK, Litwin A, Trump DL: A dramatic, objective antiandrogen withdrawal response: case report and review of the literature.J Hematol Oncol. 2008; 5 (1):21. PubMed I Full text

4. Small EJ, Halabi S, Dawson NA, et al:: Antiandrogen withdrawal alone or in combination with ketoconazole in androgen-independent prostate cancer patients: a phase III trial (CALGB 9583). J Clin Oncol 2004; 22 (6):1025-33. PubMed I Full text

5. Sweeney CJ, Chen YH, Carducci M, et al.: Chemohormonal therapy in metastatic hormone-sensitive prostate cancer. N EnglJ Med. 2015;373(8):737-46. PubMed I Full text

6. Alhanafy AM, Zanaty F, Ibrahem R, Omar S. Prognostic Factors for Hormone Sensitive Metastatic Prostate Cancer: Impact of Disease Volume. Asian Pac J Cancer Prev. 2018; 19(4):1113-1118. PubMed I Full text

Competing Interests: We are authors of this article. Our competing interests have been disclosed in the main article. 
The benefits of publishing with F1000Research:

- Your article is published within days, with no editorial bias

- You can publish traditional articles, null/negative results, case reports, data notes and more

- The peer review process is transparent and collaborative

- Your article is indexed in PubMed after passing peer review

- Dedicated customer support at every stage

For pre-submission enquiries, contact research@f1000.com 